12,06

\title{
Внутренняя структура магнитных пористых стекол и сегнетоэлектрических нанокомпозитов на их основе
}

\author{
(C) A.A. Набережнов ${ }^{1,2}$, V. Ryukhtin ${ }^{3}$, A.A. Сысоева ${ }^{1}$ \\ ${ }^{1}$ Физико-технический институт им. А.Ф. Иофффе РАН, \\ Санкт-Петербург, Россия \\ ${ }^{2}$ Санкт-Петербургский политехнический университет Петра Великого, \\ Санкт-Петербург, Россия \\ ${ }^{3}$ Nuclear Physics Institute, \\ Řež near Prague, Czech Republic \\ E-mail: alex.nabereznov@mail.ioffe.ru
}

(Поступила в Редакцию 6 апреля 2016 г.

В окончательной редакции 11 июля 2016 г.)

Методом малоуглового рассеяния нейтронов исследована внутренняя структура пустых пористых микрои макропористых магнитных стекол и нанокомпозитов на их основе, содержащих внедренные в поры $\mathrm{NaNO}_{2}$ и $\mathrm{KNO}_{3}$. Получены оценки характерных размеров частиц магнетита в матрицах и размеров наночастиц внедренных сегнетоэлектрических материалов. Показано, что в микропористых стеклах при $0.35 \mathrm{~nm}^{-1}<Q<1.7 \mathrm{~nm}^{-1}$ в рассеянии наблюдаются две характерные области: первая хорошо соответствует закону Порода $Q^{-4}$ (гладкой поверхности), а вторая - массовому фракталу, отражающему внутреннюю структуру каналов в микропористом стекле. Для макропористых стекол во всей области $0.35 \mathrm{~nm}^{-1}<Q<1.7 \mathrm{~nm}^{-1}$ интенсивность рассеяния $I(Q) \sim Q^{-n}$ с $\alpha=3.96 \pm 0.02$, т.е. в этих стеклах присутствует система каналов с достаточно гладкой поверхностью.

Работа выполнена при финансовой поддержке РНФ (проект 14-22-00136). Измерения в NPI CAS Řež проведены при помощи инфраструктуры CANAM при поддержке MŠMT (проект LM2011019).

DOI: 10.21883/FTT.2017.02.44064.124

\section{1. Введение}

Для исследования влияния размерного эффекта на макроскопические физические свойства используются различные подходы, и одним из них является создание нанокомпозитных материалов (НКМ) на основе искусственных или природных пористых матриц, обладающих развитой системой каналов нанометровых диаметров. В качестве исходных диэлектрических матриц используются опалы, хризотиловые асбесты, цеолиты, пористые стекла, пористый кремний, мембраны из анодного оксида алюминия, мезопористые матрицы типа MCM-41 (48) [1] и SBA-15 [2] и другие материалы, поры которых заполняются различными веществами. Развитые методы создания НКМ позволяют получать материалы с внедренными в поровое пространство магнетиками, сегнетоэлектриками, полупроводниками, металлами, жидкостями и прочими веществами и исследовать влияние размерного эффекта и условий искусственно ограниченной геометрии на кристаллическую структуру, фазовые переходы, транспортные свойства и другие характеристики наноструктурированных веществ. При этом, выбирая тип матрицы и средний диаметр канала, можно проследить связь размера частицы с ее свойствами и оценить роль самой матрицы (в частности, интерфейса „матрица-внедренный материал“) и ее топологии в формировании новых свойств НКМ. Для НКМ, содержащих введенные металлы, обнаружено возникновение новых, ранее не наблюдавшихся, кристаллических фаз [3-5], резкое увеличение (в 70-100 раз) критических магнитных полей, приводящих к разрушению сверхпроводящего состояния [6,7]. Для магнитных и сегнетоэлектрических НКМ обнаружено изменение рода фазового перехода $(Ф П)[8,9]$, формирование и стабилизация новых кристаллических фаз [10-13] и другие эффекты. Пористые щелочно-боросиликатные стекла являются одним из наиболее распространенных материалов для создания НКМ, так как технология их получения хорошо отработана [14] и позволяет получать матрицы с заранее заданными и контролируемыми средними диаметрами пор от единиц до сотен нанометров. Следует отметить, что во всех вышеперечисленных случаях диэлектрических матриц сама матрица играет, в основном, пассивную роль в модификации свойств внедренных материалов, обеспечивая только условия ограниченной геометрии (не считая влияния интерфейса). Одной из возможностей сделать матрицу активной является изготовление магнитных пористых стекол с регулируемым средним диаметром пор, причем желательно присутствие магнитных свойств именно у каркаса матрицы. Тогда появляется возможность создать НКМ с пространственно-разделенными параметрами порядка: например, магнитное упорядочение реализуется в каркасе матрицы, а материал, введенный в поры, является сегнетоэлектриком. При этом оказывается возможным сосуществование обоих типов в области комнатной температуры, что является интересным уже и 
с точки зрения практического применения для создания мультифунциональных материалов. Кроме того, стекла с магнитными свойствами и пористые стекла на их основе в настоящее время находят широкое применение в медицине и биологии [15-17], а также в качестве биосенсоров, датчиков $[17,18]$ и т. п.

\section{2. Образцы и методика эксперимента}

Пластины магнитных микро- (Fe20 MIP) и макропористых (Fе20МАР) стекол размером $10 \times 10 \times 0.5 \mathrm{~mm}$ были изготовлены в ИХС РАН в рамках проекта РФФИ 11-03-00747а по технологии, изложенной в работах [19-21], на основе двухфазных стекол, полученных из исходной шихты состава $60 \%$ $\mathrm{SiO}_{2}-15 \% \mathrm{~B}_{2} \mathrm{O}_{3}-5 \% \mathrm{Na}_{2} \mathrm{O}-20 \% \mathrm{Fe}_{2} \mathrm{O}_{3}$. Средний диаметр пор составлял $5 \mathrm{~nm}$ в Fe20MIP, для Fe20MAP наблюдалось бимодальное распределение пор по диаметрам: 5 и 50-60 nm [22]. Далее в рамках совместного осуществления проекта РФФИ № 11-03-00747a (2011/2013) образцы были переданы нам для проведения исследований. Заполнение сегнетоэлектриками $\mathrm{NaNO}_{2}$ и $\mathrm{KNO}_{3}$ проводилось в ФТИ им. А.Ф. Иоффе РАН (С.-Петербург) из расплава, а в случае нитрата калия из расплава под давлением. Заполнение составляло $\sim 90 \%$ от общего порового пространства для нитрита натрия и $\sim 60 \%$ для нитрата калия, процент заполнения определялся по результатам взвешивания пустых и заполненных стекол. Внутренняя структура пустых стекол Fe20MIP и Fe20MAP при комнатной температуре исследовалась на установке малоуглового рассеяния нейтронов (SANS Small Angle Neutron Scattering) V4 (Helmholtz Zentrum Berlin, Берлин, Германия), $\lambda=6.5 \pm 0.6 \AA$. Эти же исходные и заполненные сегнетоэлектриками образцы были исследованы и на установке MAUD (Nuclear Physics Institute of the CAS, Řež near Prague, Czech Republic) на длине волны падающих нейтронов $\lambda=2.09 \AA$ [23]. Все измерения проводились при комнатной температуре. Целью проведенных исследований было изучение особенностей внутреннего устройства этих стекол и сегнетоэлектрических НКМ, полученных на их основе. Преимущество метода SANS как раз и состоит в том, что он дает возможность получить информацию о пространственной организации исследуемых образцов, в том числе о размерах частиц и об их фрактальных характеристиках.

\section{3. Результаты и обсуждение}

Рассмотрим вопрос о том, какие эффекты можно ожидать при исследовании исходных пористых стекол Fe20MIP и Fe20MAP методом SANS. В общем случае для сечения малоуглового рассеяния $d \sigma / d \Omega$ как функции переданного импульса $Q=4 \pi \sin \theta / \lambda$ (здесь $\theta-$ угол рассеяния, а $\lambda$ - длина волны падающих нейтронов) можно написать следующее выражение [24,25]:

$$
\frac{d \sigma}{d \Omega}=\frac{1}{N} \bar{\eta}^{2} V \times \int_{0}^{\infty} \gamma(r) \frac{\sin (Q r)}{Q r} 4 \pi r^{2} d r
$$

Здесь $N$ - число рассеивающих ядер в объеме образца $V$, находящемся в пучке падающих нейтронов, величина $\bar{\eta}^{2}=\overline{\left(p_{b}(r)-\bar{p}_{b}\right)^{2}}-$ флюктуации плотности длины рассеяния, а $\gamma(r)=\left\langle\eta_{i}, \eta_{j}\right\rangle_{r} / \bar{\eta}^{2}-$ корреляционная функция плотности длины рассеяния. Эта функция $\gamma(r)$ содержит всю информацию от эффектов формы и размеров неоднородностей (т.е. пор или частиц в матрице) и их взаимного расположения [25].

Для рассеяния на пористых системах выражение (1) можно упростить [25], и тогда для интенсивности рассеяния получается следующее соотношение:

$$
I(Q)=V_{p}^{2} n_{p}^{2}\left(\rho_{p}-\rho_{s}\right)^{2} P(Q) S(Q),
$$

где $V_{p}$ - объем пор, $n_{p}-$ их плотность порогового пространства, $\rho_{p}$ и $\rho_{s}$ - плотности длин рассеяния для пор и матрицы, $P(Q)$ - форм-фактор для пор (или частиц в матрице), а $S(Q)$ - структурный фактор, который определяется пространственным упорядочением пор и описывает интерференционные эффекты от рассеяния на контрасте пора-матрица.

Величина $P(Q)$ может быть рассчитана для частиц (пор) различной формы $[25]$, но в области малых $Q$ выполняется следующее общее условие:

$$
P(Q) \approx \exp \left(-\frac{Q^{2} R_{g}^{2}}{3}\right) .
$$

Здесь $R_{g}$ - радиус гирации (среднеквадратичный радиус инерции) рассеивающей частицы. Следует отметить, что при $Q R_{g} \leq 1$ (т. е. в области Гинье) величина $S(Q) \approx 1$, и все рассеяние определяется множителем $P(Q)$. При больших $Q$, в частности в области Порода, где выполняется условие $Q R_{g} \geq 1$, интенсивность рассеяния имеет вид

$$
I(Q) \sim S(Q) \sim S Q^{-(6-D)},
$$

где $D$ - фрактальная размерность, а $S$ - полная площадь интерфейса между двумя фазами. В частном случае гладкой поверхности $D=2$, тогда $I(Q) \sim Q^{-4}$, такое асимптотическое поведение носит название закона Порода [26]. Таким образом, определив показатель степени в выражении (4) из анализа данных SANS, можно получить информацию о фрактальной размерности и типе (массовый или поверхностный) фрактала. При обработке данных мы использовали выражение (2), свернутое с инструментальной функцией разрешения и с модельной функцией распределения частиц по размерам, которое предполагалось логарифмически нормальным.

На рис. 1 представлены результаты SANS, полученные на исходных пористых магнитных стеклах Fe20MAP (a) 

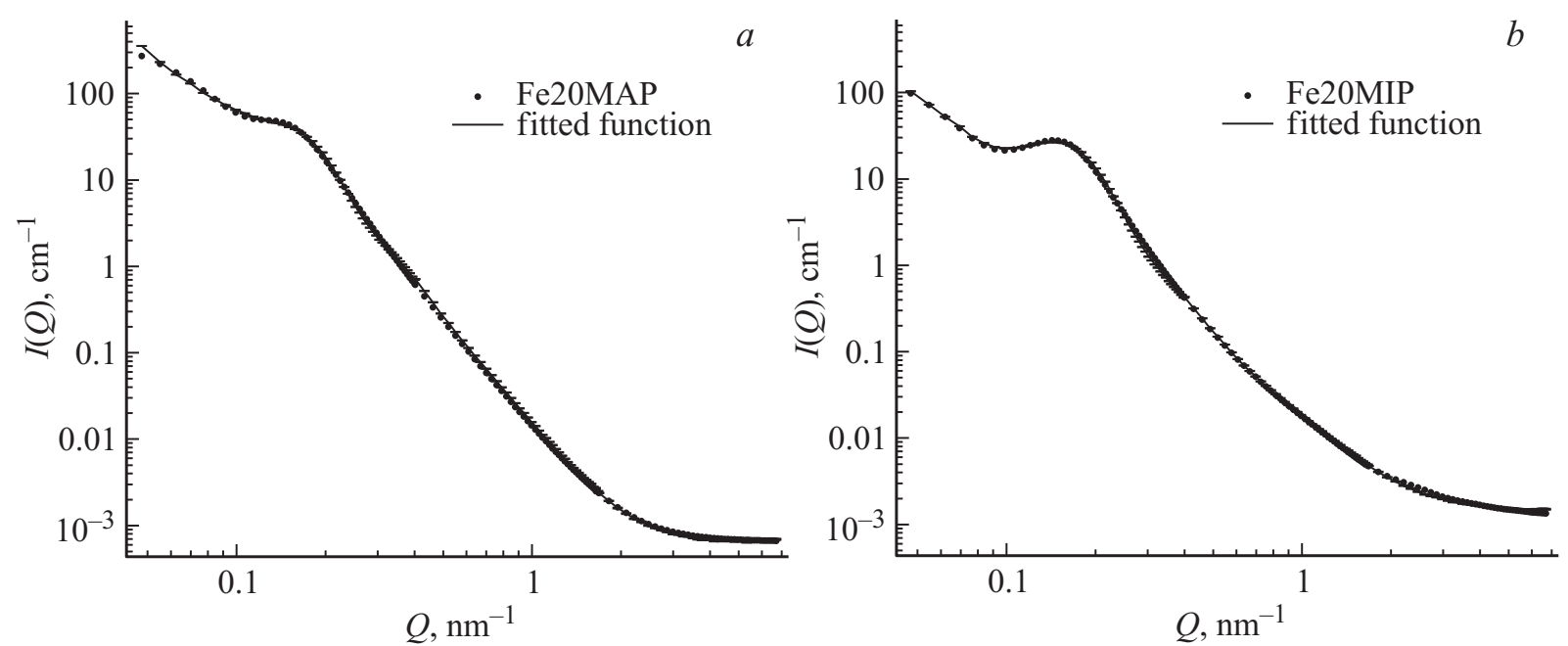

Рис. 1. Интенсивность малоуглового рассеяния на образцах Fe20MAP (a) и Fe20MIP (b). Данные получены на установке V4. Линии - результат подгонки по модели, описанной в тексте, горизонтальные черточки - величина ошибок подгонки.
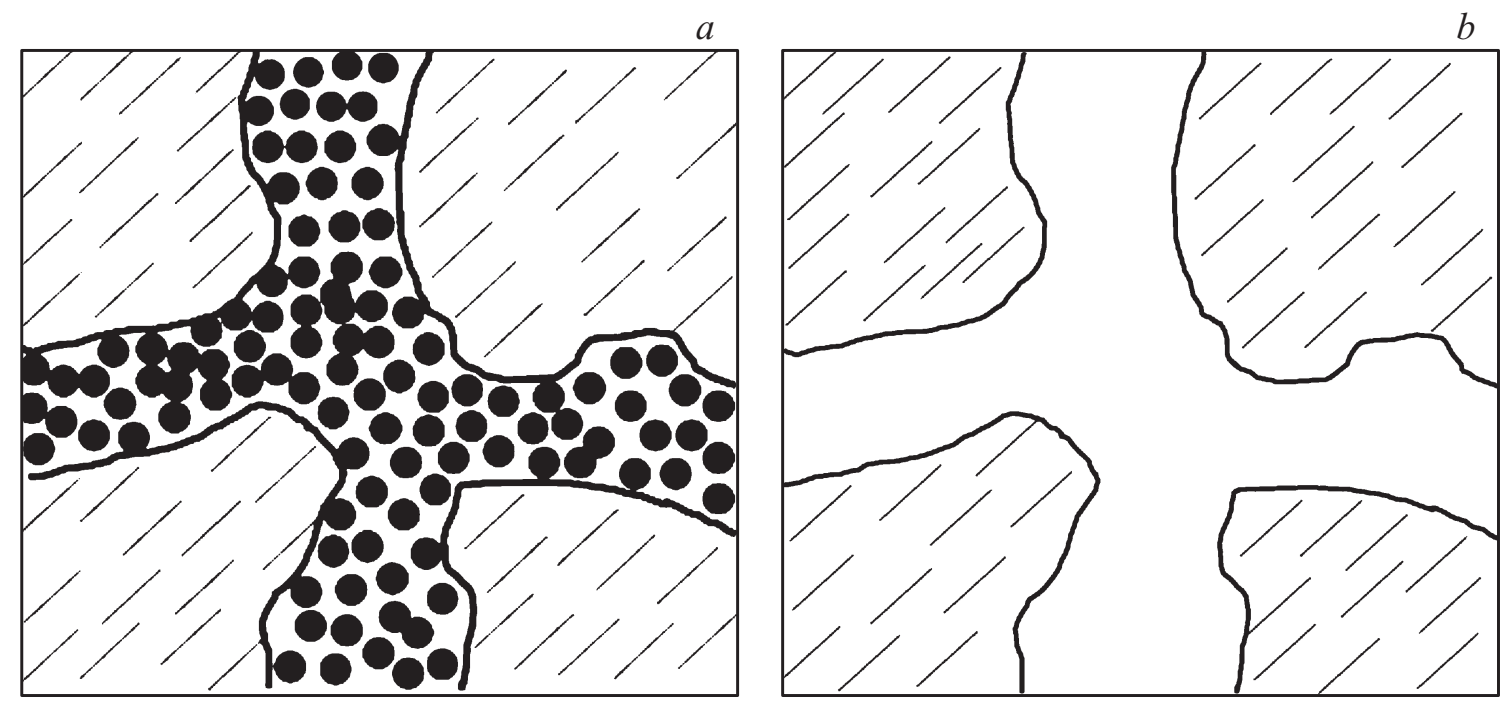

Рис. 2. Схема устройства внутренней структуры микропористых $(a)$ и макропористых $(b)$ щелочно-боросиликатных стекол согласно данным работы [28]. Черные точки на рисунке $(a)-$ вторичный кремнезем, имеющий собственную внутреннюю структуру. Штрихованные области - каркас матрицы, состоящий в этих стеклах в основном из $\mathrm{SiO}_{2}$. Черные кривые на рисунке $(a)$ выделяют область ХНФ, в которой после первого цикла травления формируется микропористая структура. Белое пространство на рисунке $(b)$ - область внутренних каналов в макропористом стекле. Схема нарисована на основании рисунков, приведенных в работе [29].

и Fe20MIP (b). Хорошо видно принципиальное различие между этими двумя зависимостями $I(Q): 1-$ для образца Fe20MIP наблюдается хорошо выделенный пик при $Q \approx 0.15 \mathrm{~nm}^{-1}$, а для второго образца он становится более размытым; 2 - поведение кривых при больших $Q$ также различно, причем для Fe20MAP явно присутствует протяженная область линейной зависимости $\log (S(Q))$ от $\log (Q)$ при больших $Q$. Сначала рассмотрим поведение наклона $I(Q)$ в области $0.35 \mathrm{~nm}^{-1}<Q<1.7 \mathrm{~nm}^{-1}$ (при $Q$ больше $1.8 \mathrm{~nm}^{-1}$ вклад некогерентного фона $B_{\text {inc в }}$ рассеяние становится большим, что затрудняет анализ). Для стекол Fe20MIP можно выделить 2 диапазона, где интенсивность $I(Q)$ разумно описывается степенной зависимостью типа $Q^{-\alpha}$ : область $0.35-0.73 \mathrm{~nm}^{-1}$, где $\alpha=3.92 \pm 0.04$, и область $0.78-1.7 \mathrm{~nm}^{-1}$, где $\alpha=2.64 \pm 0.02$. Первая область хорошо соответствует закону Порода (гладкой поверхности), а вторая - массовому фракталу [27], соответствующему внутренней структуре каналов в микропористом стекле, которые состоят из микрочастиц вторичного кремнезема, образующихся в канале после первого цикла травления при приготовлении микропористых стекол [28] (рис. 2, a). Вторичный кремнезем имеет свою сложную структуру, детальному исследованию которого 
Таблица 1. Параметры подгонки для модели, описывающей SANS на установке V4, для стекол Fe20MIP и Fe20MAP

\begin{tabular}{l|c|c|c|c}
\hline Образец & $\xi(\mathrm{nm})$ & $d(\mathrm{~nm})$ & $\eta$ & $Q_{\max }\left(\mathrm{nm}^{-1}\right)$ \\
\hline Fe20MIP & $18.30(1)$ & $40.30(1)$ & $0.0765(2)$ & 0.143 \\
Fe20MAP & $16.71(1)$ & $43.95(1)$ & $0.0965(2)$ & 0.133
\end{tabular}

Таблица 2. Параметры подгонки для модели, описывающей SANS рассеяние, полученные на установке MAUD, для стекол Fe20MIP, Fe20MAP, Fe20MIP + $\mathrm{KNO}_{3}$ и $\mathrm{Fe} 20 \mathrm{MIP}+\mathrm{NaNO}_{2}$

\begin{tabular}{l|l|l|l}
\hline \multicolumn{1}{c|}{ Образец } & \multicolumn{1}{c|}{$\mathrm{D} 1(\mathrm{~nm})$} & \multicolumn{1}{c}{$D 2(\mathrm{~nm})$} & \multicolumn{1}{c}{$D 3(\mathrm{~nm})$} \\
\hline $\mathrm{Fe} 20 \mathrm{MAP}$ & $121.5(6)$ & $39.6(5.7)$ & $12.42(0.25)$ \\
$\mathrm{Fe} 20 \mathrm{MIP}$ & $257(12)$ & $73.4(14.1)$ & $11(1)$ \\
$\mathrm{Fe} 20 \mathrm{MIP}+\mathrm{KNO}_{3}$ & $269.7(4.6)$ & $58.1(8.4)$ & $11.6(0.4)$ \\
$\mathrm{Fe} 20 \mathrm{MIP}+\mathrm{NaNO}_{2}$ & $286.7(8.7)$ & $56.7(9.4)$ & $13.3(0.5)$
\end{tabular}

посвящена работа [28]. Для стекол Fе20МАР, которые получаются в результате второго цикла травления стекла Fe20MIP, во всей области $0.35 \mathrm{~nm}^{-1}<Q<1.7 \mathrm{~nm}^{-1}$ $\alpha=3.96 \pm 0.02$, т.е. при втором цикле вторичный кремнезем из каналов в значительной степени удаляется (рис. $2, b$ ), и в результате получается система каналов с достаточно гладкой поверхностью. Отметим, что здесь закон рассеяния $I \sim Q^{-3.96}$ выполняется при изменении $Q$ более, чем порядок. Что касается области $1.7 \mathrm{~nm}^{-1}<Q<3 \mathrm{~nm}^{-1}$, то здесь и для Fe20MAР и для Fe20MIP наблюдается явно выраженное превышение рассеяния над уровнем некогерентного фона $\left(B_{\text {inc }}\right.$ при больших $Q$ является константой), которое связано с наличием внутренней структуры нанометрового масштаба в каркасе обеих матриц.

Теперь рассмотрим область аномалии при $Q \approx$ $\approx 0.15 \mathrm{~nm}^{-1}$. Для описания рассеяния в этой области мы воспользовались моделью Teubner-Strey [30,31], предложенной для двухфазных объектов и использованной, в частности, для описания данных SANS на микроэмульсиях. В этой модели интенсивность рассеяния от $Q$ описывается следующим выражением:

$$
I(Q)=\frac{8 \pi\left\langle\eta^{2}\right\rangle / \xi}{a^{2}-2 b Q^{2}+Q^{4}} .
$$

Здесь параметр $a^{2}=\left(\kappa^{2}+1 / \xi^{2}\right)^{2}$ всегда больше нуля, параметр $b=\left(\kappa^{2}-1 / \xi^{2}\right)$ может быть как положительным, так и отрицательным в зависимости от величин $\kappa=2 \pi / d$ и $\xi$. Положительная величина $b$, т.е. при $\xi>2 \pi / d$, приводит к появлению пика в рассеянии при $Q_{\max }=\sqrt{b}$, а при отрицательном $b$, т. е. при $\xi<2 \pi / d$, никакого пика в рассеянии не наблюдается. Величина $\eta^{2}=\left(\rho_{p}-\rho_{s}\right)^{2}-$ квадрат разности (контраста) плотностей длин рассеяния в выражении (2), параметр $d$ характеризует квазипериодичность двухфазной системы (характерное расстояние между частицами или характерный размер частицы данной фазы), а величину $\xi$, играющую роль корреляционной длины, можно рассматривать как меру дисперсии параметра $d$ [30].

Полученные в результате подгонки параметры (табл. 1) хорошо описывают форму и положение аномалий в рассеянии для обоих образцов.

Теперь обсудим возможные эффекты, приводящие к появлению аномалий в рассеянии при $Q \approx 0.15 \mathrm{~nm}^{-1}$ в стеклах Fe20MIP и Fe20MAP. Ранее было показано, что в обычных пористых щелочно-боросиликатных стеклах типа Vycor $[32,33]$ существует „модулированная структура“ на характерном масштабе $L \sim 2 \pi / Q_{\max }$ с $L$ порядка $30-45 \mathrm{~nm}$, причем эта величина не зависит от среднего диаметра пор, т.е. является исключительно типичной характеристикой пористых матриц. Для наших образцов роль величины $L$ играет параметр $d$. Отметим, что после второго цикла травления (стекла Fe20MAP) положение максимума сдвигается в сторону меньших $Q$, параметр $d$ увеличивается, а сам пик становится (рис. $1, b)$ не таким ярко выраженным, а более размытым. Скорее всего, это связано с тем, что в стеклах Fe20MIP существует еще один характерный масштаб, практически исчезающий при втором цикле травления. Такой эффект может быть связан с нанокластерами магнетита в порах стекла Fe20MIP. Действительно в работах $[33,34]$ было показано, что часть монодоменных (с размером $12-14 \mathrm{~nm}$ ) наночастиц магнетита самоорганизуются в крупные агломераты. В микропористых стеклах Fe20MIP такие агломераты могут возникать и внутри области (ХНФ) [20], причем их размер ограничен средним диаметром канала, в котором эта область реализуется. Этот диаметр составляет примерно $50-60 \mathrm{~nm}$, так как он, в целом, соответствует среднему диаметру канала в образцах Fe20MAP. Как уже указано ранее, при втором цикле травления [22] содержимое канала практически полностью удаляется, в том числе вытравливается и $2 / 3$ исходного оксида железа, что в результате и может приводить к уменьшению и размытию аномалии в рассеянии, а также к уменьшению $Q_{\max }$. В пользу такого сценария свидетельствует и увеличение контраста плотностей длин рассеяния $\eta$ при переходе от образца Fe20MIP к Fe20MAP (табл. 1).

Рост $I(Q)$ в области малых $Q<0.1 \mathrm{~nm}^{-1}$ связан с наличием в образцах объектов с большими размерами, что хорошо совпадает с нашими данными, полученными из анализа результатов исследования стекол Fe20MIP и Fe20MAР методом атомно-силовой и магнитно-силовой микроскопии $[34,35]$. Для исследования структурных характеристик этих объектов мы использовали двукристальную установку для малоуглового рассеяния нейтронов с высоким разрешением $\left(Q_{\min } \approx 10^{-3} \mathrm{~nm}^{-1}\right)$ MAUD. C ее помощью была исследована структура нанокомпозитных материалов на основе стекол Fe20MIP, содержащие внедренные в поры $\mathrm{NaNO}_{2}$ и $\mathrm{KNO}_{3}$, а также исходных пустых стекол Fе20MIP и Fе20MAP. На рис. $3, b$ представлены результаты, полученные для указанных исходных стекол Fе20MIP и Fe20MAP. Обработка результатов проводилась с использованием пред- 

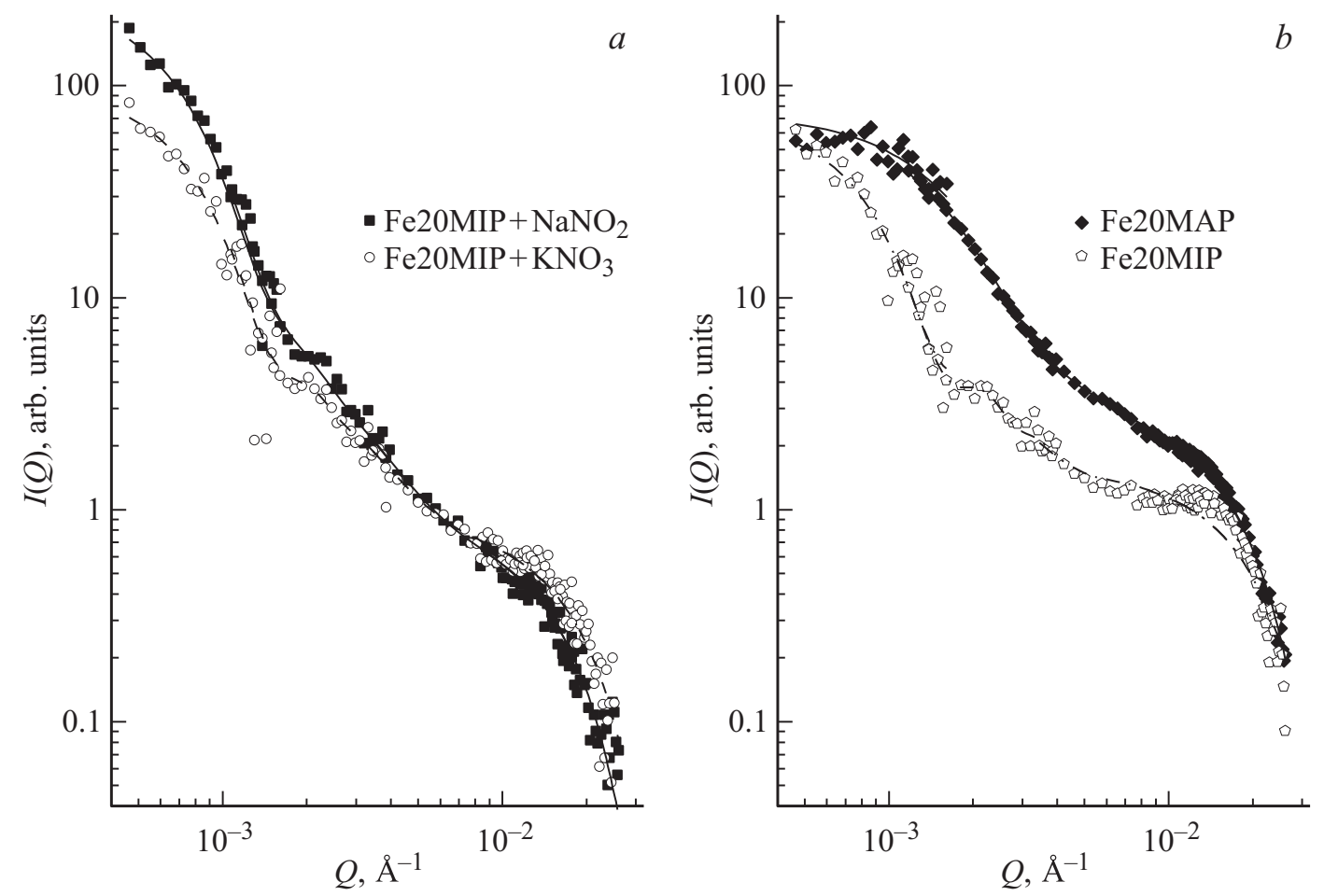

Рис. 3. Зависимость интенсивности малоуглового рассеяния от переданного импульса $Q$ для микропористых стекол с внедренными сегнетоэлектриками - Fe20MIP $+\mathrm{NaNO}_{2}$ и $\mathrm{Fe} 20 \mathrm{MIP}+\mathrm{KNO}_{3}(a)$ и для пустых пористых стекол Fе20MIP и $\mathrm{Fe} 20 \mathrm{MAP}(b)$. Данные получены на установке MAUD. Линии - результат подгонки по модели, описанной в тексте, горизонтальные черточки - величина ошибок подгонки.

положения о наличии в образцах трех типов сферических рассеивателей с распределенными по логарифмически нормальному закону размерами, которые были использованы в качестве свободных параметров подгонки. Для этих средних величин размеров были получены следующие значения (включая стекла $\mathrm{Fe} 20 \mathrm{MIP}+\mathrm{KNO}_{3}$ и $\left.\mathrm{Fe} 20 \mathrm{MIP}+\mathrm{NaNO}_{2}\right)$, приведенные в табл. 2 .

Величины $D 1$ для обоих образцов следует рассматривать как нижний предел размеров крупных агломератов, a $D 1$ очень близки к размерам монодоменных частиц магнетита в каркасе стекол, полученным из данных по рентгеновской дифракции на образцах Fe20MIP и Fe20MAP [22]. Следует отметить, что значения $D 1$ достаточно близки к размерам агломератов магнетита, которые ранее наблюдались при проведении исследований с использованием атомно-силовой и магнитно-силовой микроскопии $[34,35]$. На рис. 3, $a$ приведены зависимости $I(Q)$ (при комнатной температуре) для образцов Fe20MIP, заполненных $\mathrm{NaNO}_{2}$ и $\mathrm{KNO}_{3}$. Параметры $D 1$ и $D 3$, как и следовало бы ожидать, остались практически неизменными, а вот для $D 2$ из обработки было получено значение $57(3) \mathrm{nm}$, что несколько меньше величины $D 2$ для исходных стекол Fе20MIP. Очевидно, что это изменение связано с введением материала в поры, а сама величина $D 2$ соответствует характерному размеру внедренных в поры частиц $\mathrm{NaNO}_{2}$ или $\mathrm{KNO}_{3}$. Это хорошо соответствует ранее полученным оценкам размеров частиц $\mathrm{NaNO}_{2}$ и $\mathrm{KNO}_{3}$, внедренных в поры из расплава $[9,13]$ и подтверждает тот факт, что для микропористых стекол (со средним диаметром пор 3-7 nm) материалы в порах образуют дендритные частицы с характерным размером, значительно превосходящим средний диаметр пор.

\section{4. Заключение}

Особенности внутренней структура пустых пористых микро- и макропористых магнитных стекол и нанокомпозитов на их основе, содержащих внедренные в поры $\mathrm{NaNO}_{2}$ и $\mathrm{KNO}_{3}$, исследованы методом малоуглового рассеяния нейтронов. Показано, что в пустых стеклах Fe20MIP и Fe20MAP присутствуют частицы с характерными размерами $\sim 12 \mathrm{~nm}$, крупные агломераты с размером более $270 \mathrm{~nm}$ и области с локальным упорядочением, размер которых около $40-45 \mathrm{~nm}$. Для микропористых стекол Fe20MIP в диапазоне $0.35 \mathrm{~nm}^{-1}<Q<1.7 \mathrm{~nm}^{-1}$ установлено наличие двух областей с принципиально разными зависимостями интенсивности рассеяния $I$ от $Q^{-\alpha}$, отвечающими рассеянию на достаточно гладкой поверхности $(\alpha=3.92 \pm 0.04)$ и на массовом фрактале (область $0.78-1.7 \mathrm{~nm}^{-1}$, где $n=2.64 \pm 0.02$ ). Для макропористого стекла Fe20MAP $I \sim Q^{-\alpha}$ с $\alpha=3.96 \pm 0.02$ (pacсеяние на гладкой поверхности) практически во всем 
интервале $0.35 \mathrm{~nm}^{-1}<Q<1.7 \mathrm{~nm}^{-1}$. Получены оценки размера наночастиц $\mathrm{NaNO}_{2}$ и $\mathrm{KNO}_{3}$, внедренных в поры магнитных пористых матриц Fe20MIP, и показано, что эти наночастицы образуют в порах дендритные структуры, размеры которых примерно на порядок превосходят средний диаметр пор в данных матрицах.

\section{Список литературы}

[1] C.T. Kresge, M.E. Leonowicz, W.J. Roth, J.C. Vartuli, J.S. Beck. Lett. Nature 359, 710 (1992).

[2] D. Zhao, J. Feng, Q. Huo, N. Melosh, G.H. Fredrickson, B.F. Chmelka, G.D. Stucky. Science 279, 548 (1998).

[3] M.K. Lee, C. Tien, E.V. Charnaya , H.-S. Sheu, Yu.A. Kumzerov. Phys. Lett. A 374, 1570 (2010).

[4] M. Tanaka, M. Takeguchi, K. Furuya. Surf. Science 435, 491 (1999).

[5] А.А. Набережнов, А.Е. Совестнов, А.В. Фокин. ЖТФ 81, 49 (2011)

[6] А.А. Шиков, М.Г. Землянов, П.П. Паршин, А.А. Набережнов, Ю.А. Кумзеров. ФТТ 54, 2026 (2012).

[7] Г.Х. Панова, А.А. Никонов, А.А. Набережнов, А.В. Фокин. ФTT 51, 2098 (2009).

[8] I.V. Golosovsky, I. Mirebeau, V.P. Sakhnenko, D.A. Kurdyukov, Y.A. Kumzerov. Phys. Rev. B 72, 144409 (2005).

[9] A. Naberezhnov, A. Fokin, Yu. Kumzerov, A. Sotnikov, S. Vakhrushev, B. Dorner. Eur. Phys. J. E 12, s21 (2003).

[10] M. Kinka, J. Banys. A. Naberezhnov. Ferroelectrics 348, 67 (2007).

[11] B. Dorner, I. Golosovsky, Yu. Kumzerov, D. Kurdyukov, A. Naberezhnov, A. Sotnikov, S. Vakhrushev. Ferroelectrics 286, 213 (2003).

[12] R. Poprawski, E. Rysiakiewcz-Pasek, A. Sieradzki, A. Ciźman, J. Polanrska. J. Non-Cryst. Solids 353, 4457 (2007).

[13] A. Naberezhnov, E. Koroleva, E. Rysiakiewicz-Pasek, A. Fokin, A. Sysoeva, A. Franz, M. Seregin, M. Tovar. Phase Transitions 87, 1148 (2014).

[14] О.В. Мазурин, Г.П. Роскова, В.И. Аверьянов, Т.В. Антропова. Двухфазные стекла. Структура, свойства, применение / Под ред. Б.Г. Варшал. Наука, Л. (1991). 276 с.

[15] S. Huang, C. Li, Z. Cheng, Y. Fan, P. Yang, C. Zhang, K. Yang, J. Lin. J. Colloid Interface Sci. 376, 312 (2012).

[16] R.K. Singh, A. Srinivasan, G.P. Kothiyal. J. Mater Sci.: Mater. Medicine 20, S147 (2009).

[17] F. Hu, S. Chen, R. Yuan. Sensors Actuators B 176, 713 (2013).

[18] Y.-H. Won, H.S. Jang, S.M. Kim. Langmuir. 26, 4320 (2010).

[19] С.В. Столяр, И.Н. Анфимова, И.А. Дроздова, Т.В. Антропова. Наносистемы, наноматериалы, нанотехнологии 9, 433 (2011).

[20] О.А. Пшенко, Т.Г. Костырева, Л.Ф. Дикая, Т.В. Антропова. Физика и химия стекла 38, 858 (2012).

[21] Т.В. Антропова, И.Н. Анфимова, И.Н. Дроздова, Т.Г. Костырева, И.Г. Полякова, О.А. Пшенко, С.В. Столяр. Патент RU 2540754. Приоритет изобретения 05.12.2013. Зарегистрир. 22.12.2014. Опубл. 10.02.2015. Бюл. № 4.

[22] Т.В. Антропова, И.Н. Анфимова, И.В. Голосовский, Ю.А. Кибалин, А.А. Набережнов, Н.И. Поречная, О.А. Пшенко, А.В. Филимонов. ФТТ 54, 1977 (2012).

[23] P. Strunz, J. Šaroun, P. Mikula, P.Lukáš, F. Eichhorn. J. Appl. Cryst. 30, 844 (1997).
[24] P. Debye, A. Bueche. J. Appl. Phys. 20, 518 (1949).

[25] John D.F. Ramsay. Adv. Colloid Interface Sci. 76-77, 13 (1998).

[26] G. Porod, Kolloidn Zh. 124, 83 (1951).

[27] М.В. Авдеев, В.Л. Аксенов. УФН 180, 1009 (2010).

[28] Т.Н. Василевская, Т.В. Антропова. ФТТ 51, 2386 (2009).

[29] S.P. Zhdanov. Wiss. Z. Friedrich-Schiller-Univ., Jena. MathNaturwiss. Reihe 36, 817 (1987).

[30] M. Teubner, R. Strey. J. Chem. Phys. 87, 3195 (1987).

[31] K.V. Schubert, R. Strey, S.R. Kline, E.W. Kaler. J. Chem. Phys. 101, 5343 (1994).

[32] A. Höhr, H.-B. Neumann, P.W. Schmidt, P. Pfeifer, D. Avnir. Phys. Rev. B 38, 1462 (1988).

[33] P. Levitz, G. Ehret, S.K. Sinha, J.M. Drake. J. Chem. Phys. 95, 6151 (1991).

[34] Н.И. Поречная, А.А. Набережнов, И.А. Дроздова, И.Н. Анфимова, О.А. Пшенко. Науч.-техн. вед. СПбГПУ. Физ.-мат. науки. 2 (158), 22 (2012).

[35] A. Naberezhnov, N. Porechnaya, V. Nizhankovskii, A. Filimonov, B. Nacke. Sci. World J. 2014, 320451 (2014). 